\title{
FACTORES QUE RESTRINGEN LA COMPETITIVIDAD DE LAS EMPRESAS NACIONALES EN MATERIA TRIBUTARIA
}

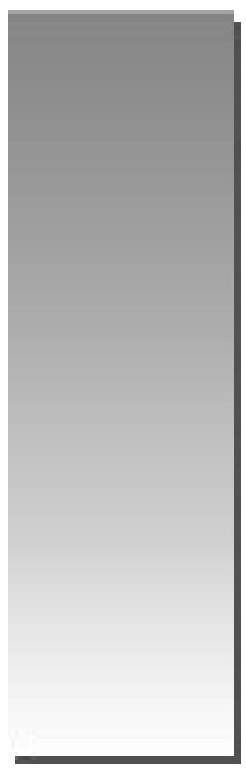

Máximo Ugarte Vega Centeno* E-mail:mugartev@unmsm.edu.pe

\section{RESUMEN}

Actualmente los sistemas tributarios deben cumplir funciones económicas para producir recursos para la producción de bienes y servicios públicos, dentro de la orientación de una política económica de estabilidad a corto plazo.

Como bien sabemos, en el Perú los ingresos que tiene el Gobierno en materia tributaria se dan principalmente por la recaudación del Impuesto General a las Ventas, Impuesto Selectivo al Consumo, Impuesto al Comercio Exterior, Impuesto a la Renta y el Impuesto a las Transacciones Financieras. Sin embargo, existe en nuestra estructura tributaria factores que restringen la competitividad, que afectan la producción y la productividad empresarial. En ese sentido se requiere de un sistema tributario con definiciones y normas claras y transparentes, sin barreras burocráticas, que sea flexible y que se adapte rápidamente a los cambios del entorno interno y externo. Este sistema pasa por la modernización o reforma del Estado, que es una exigencia del fortalecimiento institucional del país.

Palabras clave: Restricción tributaria y competitividad de las empresas.

\begin{abstract}
At the moment the tributary systems should complete economic functions to produce resources for the production of goods and public services, inside the orientation of a short term economic politics of stability.

As well we know, in Peru the revenues that the Government in tributary matter are given mainly by the collection from the General Tax to the Sales, Selective Tax to the Consumption, Tax to the External Trade, Tax to the Rent and the Tax to the Financial Transactions. However, it exists in our structure tributary factors that you/they restrict the competitiveness that you/they affect the production and the managerial productivity. In that sense it is required a tributary system with definitions and clear and transparent norms, without bureaucratic barriers that it is flexible and quickly adapted to the changes of the internal and external environment. This system goes by the modernization or reformation of the State that it is a demand of the institutional invigoration of the country.
\end{abstract}

Key words: Tributary restriction and competitiveness of the companies.

* Doctor en Estudios Internacionales. Magíster en Estudios Europeos (mercado de integración económica, comercial y financiera). Profesor Principal, Director de la Unidad de Investigaciones de la Facultad de Ciencias Administrativas de la Universidad Nacional Mayor de San Marcos. 


\section{INTRODUCCIÓN}

Los tributos están casi presentes en todas las actividades que realizan las personas naturales y jurídicas ${ }^{1}$, sin embargo nos encontramos con muchas incoherencias en nuestro sistema tributario que, además, generan distorsiones creadas por impuestos antitécnicos que podrían enmarcarse dentro del ejercicio abusivo de los derechos, configurándose como acto ilícito específico y podemos afirmar que se trata de un acto ilícito abusivo que, a diferencia del acto ilícito común en el cual se transgrede la norma legal, implica una violación solapada del ordenamiento jurídico. En esa orientación es importante analizar cómo los tributos no pueden ser concebidos simplemente como recaudadores de impuestos, instrumentos para suplir necesidades fiscales o auxiliares de programas de gobierno, sino que éstos deben tener objetivos que pueden ser acelerar el crecimiento, estabilizar la economía y generar más no restringir competitividad a las empresas en el ámbito nacional ${ }^{2}$ y de esa manera evitar el abuso del derecho; es decir en el ejercicio de un derecho se vulnera a otro derecho que puede ser de igual, inferior o superior valía, pero que sin embargo agravia intereses de terceros.

En el presente trabajo de investigación no pretendemos abarcar todos los aspectos relacionados a la empresa en materia tributaria; simplemente analizaremos desde el marco referencial las incoherencias que restan competitividad empresarial en nuestro sistema tributario, y a partir de este diagnóstico haremos propuestas de medidas compensatorias que permitan mejorar la competitividad empresarial.

\section{MARCO TEÓRICO Y PLANTEAMIENTO DE HIPÓTESIS}

De acuerdo a los criterios que toda modernización del Estado exige, especialmente en materia tributaria -enmarcado ello bajo la creciente globalización- planteamos como punto de partida la siguiente hipótesis:

La existencia de un sistema tributario inestable en el Perú genera tributos antitécnicos y restringe la competitividad de las empresas nacionales.

\section{SISTEMA TRIBUTARIO INESTABLE}

Para identificar las causas que generan un sistema tributario inestable en el país señalaremos los objetivos fundamentales que busca todo sistema tributario, que están relacionados a la reforma y modernización del Estado ${ }^{3}$, lo que implica una adecuada distribución y gestión tributaria dentro del contexto de las políticas de Estado que se proponen, con el fin de satisfacer los requerimientos y necesidades de los ciudadanos de a pie para mejorar los servicios públicos de los ámbitos de salud, agrario, educación, administración de justicia, seguridad nacional y servicios públicos e infraestructura. De otro lado la globalización y la economía de mercado exigen la modernización de los países en vías de desarrollo en su gestión pública, así como las reformas políticas, económicas y legales dentro del nuevo concepto de estado gerente y ciudadano cliente.

En ese sentido el sistema tributario, como parte del Estado, tiene como fundamentos principales acelerar el crecimiento de un país; estabilizar la actividad económica; y reasignar los recursos económicos, sectorial y regionalmente 4 . En ese contexto podemos señalar que las políticas tributarias generan efectos y cambios dentro del marco legal y, por consiguiente, en las acciones administrativas en tributación; asimismo es importante resaltar que toda tributación viene a ser expresión de una política gubernamental donde el Estado prioriza y dota de medios para atender sus necesidades financieras mediante los impuestos que considere convenientes, de acuerdo a sus objetivos económicos en la distribución de la riqueza. En aquellos objetivos en que exista desbalance presupuestal, el Estado puede recurrir a los organismos internacionales de crédito para equilibrar su presupuesto. Por eso afirmamos que un sistema tributario como el nuestro no puede ser concebido simplemente como recaudador de dinero para suplir las necesidades fiscales de un programa de gobierno sino que debe ser todo lo contrario $^{5}$. Es decir, todo sistema tributario tiene como objetivo fundamental acelerar el crecimiento, estabilizar la actividad económica y reasignar los recursos económicos en los ámbitos nacional, sectorial y regional; en ese sentido no puede ser concebido simplemente como recaudador de impuestos o caja chica para suplir necesidades fiscales o auxiliar de un programa de gobierno ${ }^{6}$.

Actualmente todo sistema tributario debe cumplir funciones económicas, como:

- Generar recursos necesarios para la producción de bienes y servicios públicos.

- Reasignar recursos hacia fines deseables en la política económica. 
- Ayudar a estabilizar la economía de un país a corto plazo.

- Asimismo, la combinación de los efectos económicos del aparato tributario como consecuencia de un sistema tributario puede, también, incentivar las exportaciones; la promoción de la formación de capitales; atraer la inversión en industrias y reducir el consumo.

Estas consideraciones deberían ser tomadas en cuenta al plantear las diversas medidas económicas e inclusive como parte de medidas y políticas tributarias del Estado.

Los antecedentes más inmediatos en el Perú los encontramos a finales del siglo XX. La reforma del Estado Peruano era una necesidad ante la quiebra institucional por la que venia atravesando el país, y al mismo tiempo por las exigencia de insertarnos en el nuevo sistema económico, comercial y financiero internacional que empezaba a gestarse. Se promulgó una Constitución Política (muy discutida hasta ahora) y se inició una reforma estructural y legal que aún perdura hasta nuestros días, donde se incorpora el nuevo concepto de economía social de mercado en el Artículo 58 bajo la premisa de

“...la iniciativa privada es libre. Se ejerce una economía social de mercado. Bajo este régimen, el Estado orienta el desarrollo del país y actúa principalmente en las áreas de promoción de empleo, salud, educación, seguridad, servicios públicos e infraestructura",

aspectos fundamentales para la orientación de las reformas estructurales del Estado.

Para eliminar el déficit fiscal se genera el proceso de privatización de las empresas públicas de los ámbitos minero, pesquero, comunicaciones, energía, financiero; reduciéndose además la participación del Estado en los sectores de hidrocarburos y electricidad, en la modalidad de ventas y concesiones a empresas privadas como una forma de promover las inversiones, con resultados que siguen generando opiniones diversas. Ello nos lleva a analizar el sistema tributario como una forma de incentivar la inversión y el ahorro, que muchas veces no ha contado con un análisis exhaustivo de costo-beneficio para evaluar la efectividad de programas $^{7}$. En ese sentido podemos decir que los problemas generados por la actual estructura tributaria-incoherente y dispareja- requieren de una serie de cambios pero más que nada de una reforma integral del sistema dentro del marco jurídico de una economía de mercado que debe garantizar la aplicación de los principios básicos que comprende el orden tributario-económico y que son básicamente recogidos en la Constitución Política $^{8}$ y demás normas jurídicas, donde el rol del Estado es establecer y hacer cumplir las leyes sin caer en el abuso del derecho como un fenómeno social y no como concepto jurídico?

\section{TRIBUTOS ANTITÉCNICOS Y LA RESTRICCIÓN DE LA COMPETITIVIDAD EN LAS EMPRESAS NACIONALES}

Por lo anteriormente mencionado podemos analizar los efectos que tiene la inestabilidad de nuestro sistema tributario, y podemos proponer la mejor manera de reactivar la economía nacional y perfeccionar el sistema tributario. Desde ese marco referencial trataremos de responder algunas interrogantes, así como proponer propuestas que eviten las restricciones de las empresas.

Factores que restringen la competitividad de las empresas nacionales

- Factores que limitan. El impuesto extraordinario a los activos netos antes FONAVI u Impuesto de Solidaridad (IS), Ley № 26699 que hoy no está en vigencia; Impuesto General a las Ventas (IGV) en la compra-venta a plazos; y el Impuesto a las Transacciones Financieras (ITF).

- Propuestas de medidas compensatorias. La ampliación de la base tributaria; la reestructura de las actuales tasas del Impuesto Selectivo al Consumo (ISC) a los bienes sanitarios; y la realización de operaciones permanentes para frenar el contrabando, la adulteración y falsificación de productos.

- Propuesta de compensaciones. Derogar el sistema de suspensión de importaciones (es una medida para-arancelaria), que contradice el Decreto Ley 668 que proclama la libertad de comercio exterior e interior.

- Cuestionamientos desde el punto de vista empresarial. Los elevados precios de la energía y las telecomunicaciones que se califican como sobrecostos indirectos, porque afectan la producción y la productividad empresarial.

- Lo que se propone mantener. El arancel de aduanas con niveles escalonados. También se propone definir con más claridad, desde el 
punto de vista económico-comercial del Perú, nuestra proyección con la Comunidad Andina; Tratado de Libre Comercio con Estados Unidos, política bilateral y los posibles tratados con la Unión Europea, Canadá, China, México y algunos países miembros de la APEC.

- Propuestas para incentivar la demanda. Incrementos salariales libres de tributos; la reducción de la carga tributaria de las rentas de trabajo (actualmente los trabajadores soportan casi un 33\%), y la carga impositiva al trabajador en planilla, ya que los trabajadores tributan casi igual que las empresas, lo que viene a ser una distorsión. También se propone la reducción de los sobrecostos como Seguro Social, hoy EsSALUD; Impuesto a la Renta, cuya carga es elevada; el Impuesto Selectivo al Consumo de algunos bienes específicos; Impuesto General a las Ventas; Impuesto a la Cultura (libros $12 \%$ y espectáculos culturales $87 \%$ ). Finalmente sugerimos la promoción a la pequeña y microempresa, creando un régimen tributario especial para las micro y pequeñas empresas a fin de lograr sus formalización. Asimismo, para mejorar el control se propone la recaudación y la administración fiscal del IGV y la revisión de exoneraciones; y corregir los problemas de inseguridad jurídica, los delitos aduaneros, adulteración y falsificación de productos y falta de estadísticas oficiales de los principales indicadores económicos.

A partir de este diagnóstico se han podido identificar las distorsiones y restricciones en materia tributaria que restan competitividad a las empresas.

\section{ANÁLISIS Y DISCUSIÓN}

Como bien sabemos actualmente en el Perú los ingresos que tiene el Estado en materia tributaria, es decir los tributos para el gobierno central, se dan principalmente por:

- Impuesto a la Renta ${ }^{10}$, impuesto único a la venta, que grava utilidades de las personas jurídicas (empresas) y los ingresos de las personas naturales.

- Impuesto General a las Ventas que grava la venta en el ámbito nacional de bienes muebles, grava el valor agregado en cada fase de la producción y circulación de bienes y servicios, y que viene a ser uno de los más altos a nivel regional, siendo su tasa de $17 \%$ más el $2 \%$ del Impuesto de Promoción Municipal, que equivale a una tasa acumulada de 19\% hasta el 31 de diciembre de 2008.

- Impuesto Selectivo al Consumo que es aplicable a un conjunto de bienes, bienes de importación y a la venta en el país de los bienes cuando es efectuada por el importador; asimismo se grava principalmente al combustible, cerveza, aguas, gaseosas, cigarrillos, automóviles, etc.

- Impuesto a las Transacciones Financieras (ITF).

- Impuesto al Comercio Exterior; Importaciones y Exportaciones (Derechos Arancelarios). En la actualidad la economía peruana es una de las más abiertas de la región pues su nivel arancelario promedio se situará en $1.81 \%$ en el 2008 , luego que en el año 2000 se ubicaba en un promedio de $10.9 \%$.

Además de los anteriores, los principales tributos que integran el Sistema Tributario peruano son los siguientes:

- Tributos para los Gobiernos Locales. Impuesto predial, que grava a los predios urbanos y rústicos; Impuesto de Alcabala que grava las transferencias de inmuebles a título oneroso o gratuito; y el Impuesto al patrimonio vehicular, que es anual y grava a la propiedad de los vehículos (automóviles, camionetas y station wagons) fabricados en el Perú o importados, con una antiguiedad no mayor de tres años. Otros Tributos. Contribución a la Seguridad Social, que en el caso de los afiliados regulares en actividad tiene una tasa del $9 \%$ y en el caso de los afiliados potestativos los aportes varían según el plan elegido; Contribuciones al Servicio Nacional de Capacitación para la Industria Técnico Industrial (SENATI), que grava al total de las remuneraciones que pagan a sus trabajadores las empresas que desarrollan actividades industriales manufactureras en la Categoría $D$ de la Clasificación Internacional Uniforme (CIIU), con una tasa de $0.75 \%$; y la Contribución al Servicio Nacional de capacitación para la Industria de la Construcción (SENCICO), donde aportan las personas naturales y jurídicas que construyan para sí o para terceros dentro de la actividades comprendidas en la Gran División 45 de la CIIU de las Naciones Unidas (revisión 3).

Los contribuyentes, en relación a los impuestos, se dividen en contribuyentes domiciliados y contribuyentes no domiciliados, así como en 
personas naturales y jurídicas. En ese sentido, las fuentes de información y la base datos de la economía y de los contribuyentes (personas naturales y jurídicas) son importantes en todo el proceso de políticas tributarias para determinar las fuentes de ingreso tributario. Esta información minuciosa de las declaraciones de impuestos y de la economía nacional resulta de mucha utilidad para analizar las modificaciones en los ingresos a la renta. La legislación tributaria permite la información de los contribuyentes para luego poder simular los efectos en las modificaciones de la Ley y, de esa manera, calcular sus efectos sobre los ingresos; información económica que permitirá a los analistas hacer el seguimiento de los efectos en los impuestos indirectos ${ }^{11}$.

Las reflexiones sobre el sistema tributario están a la orden del día. Hay quienes sugieren que las limitaciones en los países en desarrollo, en este caso el Perú, no se deben a la falta de información primaria sino -fundamentalmente- a la falta de experiencia técnica para organizar y administrar dicha información. Inicialmente no existían programas de fiscalización para los contribuyentes que no pagasen impuestos y las sanciones en Unidades Impositivas Tributarias (UIT) ${ }^{12}$ no eran efectivas por falta de acotación de oficio o una fiscalización inmediata en caso de cierre de locales. En la actualidad la SUNAT, mediante el programa de fiscalizaciones rápidas tipo compulsa, realiza un seguimiento a los contribuyentes en relación al pago de los impuestos del IGV, ISC, Impuesto a la Renta, y al cruce de facturas en las distintas empresas, añadiendo el espionaje tributario mediante fedatarios que simulan ser simples compradores, situación que en parte ha sustituido los problemas sobre los impuestos.

Otra limitación que podemos encontrar es la excesiva exoneración en los impuestos especialmente arancelarios que se han dado de forma gradual y que han ido disminuyendo ${ }^{13}$. Sin embargo, si tomamos en consideración desde el punto de vista de la política tributaria que el objetivo es direccionar la inversión y generar mayores ingresos fiscales, vemos que esta situación solo se orienta al aumento de ingresos fiscales por el programa económico de economía de mercado liberal. Es de resaltar también que pese a haberse derogado algunos impuestos denominados antitécnicos ${ }^{14}$ -no solo por su ilegalidad sino por sus efectos en la burocratización de la administración y los obstáculos para el cumplimiento de los contribu- yentes- estos siguen manteniéndose y otras veces son propuestos por el propio Poder Ejecutivo para suplir lo no recaudado o las deficiencias que se pudieran presentar en la economía del país. En ese sentido el Ministerio de Economía y Finanzas (MEF) recurre a impuestos antitécnicos como el Impuesto a las Transacciones Financieras (ITF) y el Impuesto Temporal a los Activos Netos (ITAN) para reemplazar los ingresos dejados de percibir por la anulación del pago anticipado del Impuesto a la Renta (IR) y el punto adicional del Impuesto General a las ventas (IGV).

La SUNAT, como organismo recaudador de tributos, a principios del año 2000, iniciaría el cruce de información mediante el sistema de identificación de los contribuyentes individuales, utilizando la base de datos directamente relacionada con el Documento Nacional de Identidad (DNI), situación que hasta la fecha ha posibilitando una mejor información en cuanto al cumplimiento tributario. Sin embargo, en relación de las exoneraciones tributarias, la elusión y evasión tributaria ${ }^{16}$, siguen siendo preocupante los datos que se consignan. La evasión hace que se logre una recaudación $40 \%$ menor de lo que debería ser, que en términos monetarios asciende a los S/. 8 mil millones al 2006. En relación a las exoneraciones tributarias en algunas regiones o actividades, cada año se incrementa el monto dejado de percibir, y en el 2005 las exoneraciones llegaron a costar $\mathrm{S} / .6$ mil millones a la caja fiscal frente a los S/. 3,500 del $2002^{17}$. En síntesis, las pérdidas por exoneraciones tributarias aumentaron y el costo de estas exoneraciones tienen un impacto elevado que, para ser compensado requiere que el Estado aplique impuestos que carecen de sustento técnico. En ese sentido el Fondo Monetario Internacional (FMI) y el Banco Mundial (BM) emitieron un informe recomendando al Perú la eliminación de estos impuestos.

En las democracias modernas y fuertes se planteó, años atrás, el debate de la sociedad de bienestar y la interrogante de cómo lograrla era simplemente con el cumplimiento de dos razonamientos: menos impuestos y mayor poder adquisitivo de las personas. En ese sentido, las críticas al sistema tributario provienen de los diferentes sectores de la sociedad mientras se aumenta el IR y se crean los impuestos antitécnicos que distorsionan el Sistema; pese a ello el Perú goza de holgura fiscal producto de una sobrerecaudación y se insiste en mantener impuestos como el ITAN, ITF y el $1 \%$ adicional del IGV. En el caso del IGV, la 
evasión alcanza el $45 \%$ que en cifras alcanza los s/. 9 mil millones. Como bien sabemos, el aumento de la tasa del IGV se generó hace cuatro años en reemplazo del impuesto que afectaba a la telefonía fija y celular, con la promesa del Gobierno que este aumento sería excepcional y aplicable hasta el 2004; sin embargo ya estamos ad portas del 2008 y seguimos soportando este impuesto.

Si el Ejecutivo busca elevar la recaudación debe incentivar la inversión que como consecuencia traería trabajo y formalidad, teniendo en consideración que los que ganan más pagarán más. De esta manera lograremos que esos contribuyentes que pueden pagar los impuestos y que tienen por costumbre evadirlos, como es el caso de las empresas pequeñas y medianas que están en la informalidad, sigan actuando de espaldas al país y dejemos de cargar impuestos al empleado que está en planilla quien paga el impuesto a la renta obligatoriamente; ese es uno de los muchos ejemplos que tenemos como se distorsiona el sistema tributario.

Por eso afirmamos que el desenvolvimiento económico en una sociedad solo es posible en base a la regulación de la normas de convivencia no solo consuetudinaria sino también de aquellos que impliquen un Estado de Derecho regulado por normas jurídicas coherentes que permitan relaciones tributarias, económicas, equitativas.

\section{CONCLUSIONES}

- Un sistema tributario con definiciones y normas claras, transparentes y desburocratizadas, que además sea flexibles para adaptarse a los posibles cambios en el entorno interno y externo, es una necesidad. En relación a su aplicación debe ser estable y de fácil interpretación por quienes ejercen potestad administrativa, y a su vez debe incluir mecanismos de sanción por incumplimiento.

- Fortalecer la competitividad mediante normas tributarias claras y que tengan aplicación transparente por las entidades del Estado y los sistemas reguladores del mercado; de esta manera se restringirán las prácticas que restan competitividad a las empresas.

- Fortalecer la institucionalidad en el país para establecer un sistema tributario general y equitativo, que amplíe y fortalezca la base de contribuyentes. Asimismo, mejorar la eficiencia y calidad del gasto público; de esta manera se racionalizarán las exoneraciones y beneficios tributarios así como la disminución de la evasión y elusión.

- Un sistema tributario pasa por fortalecer las políticas tributarias de estrategias de apertura comercial, promoviendo el comercio exterior, usando para ello planes estratégicos nacionales y regionales.

- Por ultimo, podemos decir que la modernización o reforma del Estado pasa por los cambios en las estructuras del Estado en el ámbito político y económico, evaluando el marco normativo institucional, entre ellos destaca el sistema tributario cuya problemática radica principalmente en un sistema inestable y en la existencia de tributos que restringen la competitividad de la empresas y que deben ser eliminados como los cobros antitécnicos y las exoneraciones tributarias. Adicionalmente se debe intensificar la lucha contra la evasión, el contrabando y ampliar la base de los contribuyentes, ya que son los mismos los que pagan siempre. La necesidad de la ampliación cualitativa y cuantitativa de la base de los contribuyentes es una exigencia justa dentro de un contexto social tomando en consideración el principio de igualdad tributaria y el reparto equitativo de los tributos dentro de un Estado de Derecho.

\section{NOTAS}

1. Sobre el tributo véase Seijas Rengifo, Teresa de Jesús. (2005). Derecho Tributario y Derecho Procesal Tributario, segunda edición, Talleres Gráficos, pp. 441 y ss.

2. Ver Sistema Nacional de Ciencia, Tecnología e Innovación Tecnológica (SINACYT). Plan Nacional Estratégico de Ciencia, Tecnología e Innovación para la competitividad y el Desarrollo Humano-PNCTI 2006-2021. Lima, Abril 2006.

3. Véase CADE-2003. Institucionalidad: Reglas claras para la inversión. Documentos previos en XLI Conferencia Anual de Ejecutivos del 20 al 22 de noviembre de 2003, Ica, 2003.

4. Sobre el Sistema Tributario véase Chávez Ackerman, Pascual. (1993). Tratado de Derecho Tributario. Lima, Editorial San Marcos.

5. En relación a los tributos y sus elementos que contienen ver Sotelo Castañeda, Eduardo y Vargas León, Luis. En torno a la definición de tributo: Un vistazo a sus elementos esenciales; en Ius veritas, №17, Lima 1998; véase también Sanabria Ortiz, Rubén. (1997). Comentarios al Código tributario y los ilícitos tributarios: Antecedentes, concordancias, jurisprudencia, legislación comparada y notas de doctrina. Tercera edición. Lima, Editorial San Marcos.

6. Ver Las Heras, Jorge. La evasión fiscal, origen y medida de acción para combatirla; en jorgelasheras@aol.com

7. Ver Vasquez Tarazona, Catya. La modernización y el sistema Tributario; en http//www.congreso.gob.pe/biblio/art_9.htm, p.11. 
8. Véase, el Capítulo IV del Régimen Tributario y Presupuestal. Artículo $74^{\circ}$ y ss. de la Constitución Política del Perú de 1993.

9. Véase Rotonda, Mario. (1965). Lábuso del diritto; en Revista di Diritto Civile, p.116.

10. En el Perú el Impuesto a la Renta está dividido en cinco categorías, además del tratamiento especial para las rentas percibidas de fuente extranjera. Primera categoría de las rentas reales, ya sea en efectivo o en especie, del arrendamiento o subarrendamiento, el valor de las mejoras provenientes de los predios rústicos y urbanos o bienes muebles. Segunda categoría conformada por intereses por colocación de capitales, regalías, patentes, rentas vitalicias, derechos de llave, otros. Tercera categoría que comprende, en general, los derivados de actividades comerciales, industriales, de servicios o negocios. Cuarta categoría que corresponde a las rentas obtenidas por el ejercicio individual de cualquier profesión, ciencia, arte u oficio, y la quinta categoría donde se encuentran las rentas obtenidas por el trabajo personal prestado en relación de dependencia.

11. Véase Sanabria O, Rubén. (2001). Derecho Tributario e Ilícitos tributarias. Quinta edición. Gráfica Horizonte.

12. La Unidad Impositiva Tributaria (UIT) es un valor de referencia utilizado por las normas tributarias para determinar las bases imponibles, limites de afectación, deducción, para aplicar sanciones, etc. Su valor se determina considerando los supuestos macroeconómicos para cada ejercicio o año.

13. Sobre el régimen tributario en el Perú ver Sandoval Aguilar, Luis. (2006). Derecho tributario aduanero-valor en aduana y su aplicación en el Perú. Editorial Normas Legales, p. 21 y ss.

14. Ver Hugo Vizcardo, Wilfredo. (2004). El ilícito tributario. Lima, Biblioteca de Textos Universitarios, pp.14 y ss. así como el Capítulo II.

15. La Superintendencia Nacional de Administración Tributaria (SUNAT) es, de acuerdo a su ley de creación, Ley № 24829 y a su Ley General aprobada por Decreto Legislativo $\mathrm{N}^{\circ}$ 501, una institución pública descentralizada del Sector Economía y Finanzas, dotada de personería jurídica de derecho público, patrimonio propio y autonomía económica, administrativa, funcional, técnica y financiera que, en virtud a lo dispuesto por el Decreto Supremo $\mathrm{N}^{\circ}$ 061-2002-PCM, expedido al amparo de lo establecido en el Numeral 13.1 del Artículo $13^{\circ}$ de la Ley $\mathrm{N}^{\circ} 27658$, ha absorbido a la Superintendencia Nacional de Aduanas, asumiendo las funciones, facultades y atribuciones que por ley correspondían a esta entidad. (Artículo $3^{\circ}$ del Reglamento de Organización y Funciones de la SUNAT, aprobado mediante D.S. 115-2002-PCM publicado el 28 de diciembre de 2002).

16. Véase Villegas, Héctor. (2001). Evasión tributaria: un mal social, en Revista El contador público, Octubre de 2001.

17. Ver el diagnóstico de Chung, Manini. La República, 4 de Agosto de 2006.

\section{BIBLIOGRAFÍA}

CHÁVEZ ACKERMAN, PASCUAL. (1993). Tratado de Derecho Tributario. Lima, Editorial San Marcos.
CHUNG, MANINI. (2006). Diagnóstico, en La República, 4 de Agosto del 2006.

CONFERENCIA ANUAL DE EJECUTIVOS (CADE). (2003). Institucionalidad: Reglas claras para la inversión; documentos previos en XLI CADE. Ica, 20,21 y 22 de noviembre, 2003.

HERAS, JORGE. La evasión fiscal, origen y medida de acción para combatirla; en jorgelasheras@ aol.com

HUGO VIZCARDO, WILFREDO. (2004). El ilícito tributario. Lima, Biblioteca de Textos universitarios.

ROTONDA, MARIO. (1965). Lábuso del diritto; en Revista di Diritto Civile.

SANABRIA O., RUBÉN. (1997). Comentarios al Código Tributario y los ilícitos tributarios: antecedentes, concordancias, jurisprudencia, legislación comparada y notas de doctrina. (Tercera Edición). Lima, Editorial San Marcos.

SANABRIA O., RUBÉN. (2001). Derecho Tributario e Ilícitos tributarias. (Quinta Edición). Gráfica Horizonte.

SANDOVAL AGUILAR, LUIS. (2006). Derecho tributario aduanero - valor en aduana y su aplicación en el Perú. Editorial Normas Legales.

SEIJAS RENGIFO, TERESA DE JESÚS. (2005). Derecho Tributario y Derecho Procesal Tributario. Segunda edición. Talleres Gráficos.

SISTEMA NACIONAL DE CIENCIA, TECNOLOGÍA E INNOVACIÓN TECNOLÓGICA (SINACYT). (2006). Plan Nacional Estratégico de Ciencia, Tecnología e Innovación para la competitividad y el Desarrollo Humano - PNCTI 2006 - 2021. Lima, abril de 2006.

SOTELO CASTAÑEDA, EDUARDO y VARGAS LEÓN, LUIS. (1998). En torno a la definición de tributo: Un vistazo a sus elementos esenciales; en Ius Veritas, Edición Nº17. Lima 1998.

VÁSQUEZ TARAZONA, CATYA. La modernización $y$ el Sistema Tributario. Ver en: http//www. congreso.gob.pe/biblio/art_9.htm.

VILLEGAS, HÉCTOR. (2001). Evasión tributaria: un mal social; en Revista el Contador Público, Octubre de 2001.

\section{NORMAS Y LEYES}

Constitución Política del Perú (1993). 